\title{
ANÁLISE DOS FOCOS DE QUEIMADAS E SEUS IMPACTOS NO MARANHÃO DURANTE EVENTOS DE ESTIAGEM NO PERÍODO DE 1998 A 2016
}

\author{
BEZERRA, Denilson da Silva-denilson_ca@yahoo.com.br \\ Universidade CEUMA
}

DIAS, Bruna Caroline Correia - bruninhacorreia_25@hotmail.com
Universidade CEUMA

\author{
RODRIGUES, Leonardo Henrique de Sá - leohsr@gmail.com \\ Universidade CEUMA
}
TOMAZ, Raoni Blom - raonitomaz@gmail.com
Universidade CEUMA
SANTOS, André Luis Silva dos - andresantos@ifma.edu.br Instituto Federal do Maranhão / IFMA
SILVA JUNIOR, Celso Henrique Leite - celso.junior@inpe.br Instituto Nacional de Pesquisas Espaciais / INPE

\begin{abstract}
RESUMO: O Maranhão apresenta grande variedade de ecossistemas e biomas devido à sua localização entre os climas úmido da Amazônia Legal, e o semiárido do Nordeste brasileiro, se destacando assim como um verdadeiro conjunto de ambientes transacionais. O estado não apresenta as quatro estações do ano bem definidas, apenas um período chuvoso que dura aproximadamente os primeiros seis meses do ano, seguido por um período de estiagem que pode variar de julho a dezembro. No período da estiagem é possível observar a grande ocorrência de focos de queimadas no território maranhense. O objetivo do presente estudo é avaliar a ocorrência sazonal e os impactos dos focos de queimadas no Maranhão, tomando-se como referência o intervalo de tempo compreendido de 1998 a 2016. O procedimento metodológico adotado consistiu em uma revisão bibliográfica e de busca de dados/informações em instituições que atuam direta e/ou indiretamente com a temática. De 1998 a 2016 foram notificados 374.883 focos de queimadas pelos satélites do Programa de Monitoramento de Queimadas do INPE para o estado do Maranhão, sendo os anos com maior ocorrência foram 2015 e 2012 com respectivamente $31.595(8,43 \%)$ e $30.138(8,04 \%)$ dos focos registrados para o período monitorado na presente pesquisa. Cabe ressaltar o forte padrão sazonal observado para a ocorrência dos focos de queimadas, uma vez que, $95,51 \%$ dos focos de queimadas ocorreram no período de estiagem maranhense, um montante correspondente a 358.016 focos. Todos os anos, os impactos provocados pelas queimadas no Maranhão provocam prejuízos em várias dimensões (social, econômica e ambiental); contudo sua mensuração não constitui uma tarefa trivial, o que implica afirmar que há uma grande lacuna de conhecimento sobre os efeitos das queimadas sazonais presentes na área de transição entre a Amazônia Legal e o Cerrado brasileiro, onde o Maranhão está localizado.
\end{abstract}

PALAVRAS-CHAVES: Amazônia legal. Cerrado brasileiro. Área de transição. Focos de queimadas. Período de estiagem/chuvoso.

ANALYSIS OF THE BURNS AND THEIR IMPACTS IN MARANHÃO STATE DURING STORAGE EVENTS IN THE PERIOD OF 1998 TO 2016

ABSTRACT: The Maranhão presents a great variety of ecosystems and biomes due to its location between the moist climates of the Legal Amazon and the semi-arid region of the Brazilian Northeast, standing out as a true set of transactional environments. The state 
does not have the four well-defined seasons, only a rainy period that lasts approximately the first six months of the year, followed by a dry period that can vary from July to December. During the dry period can be observed the high incidence of burnt focus in Maranhão territory. The objective of the present study is to evaluate the seasonal occurrence and impacts of burnt focus in Maranhão, taking as a reference the period of 1998-2016. The adopted methodological procedure consisted of a literature review and search of data / information in institutions that act directly and / or indirectly with the theme. From 1998 to 2016, 374,883 burnt focus were reported by the satellites of the Program of Monitoring of Burns of INPE for the state of Maranhão, with the most occurring years being 2015 and 2012 with respectively 31,595 (8.43\%) and 30.138 $(8.04 \%)$ of the focus recorded for the period monitored in the present study. It is worth noting the strong seasonal pattern observed for the occurrence of burnt focus, since, $95.51 \%$ of the fires occurred in the dry period of Maranhão, an amount corresponding to 358,016 spots. Every year, the impacts caused by the fires in Maranhão cause losses in several dimensions (social, economic and environmental); however, its measurement is not a trivial task, which implies affirming that there is a great knowledge gap on the effects of seasonal burnt in the transition area between the Legal Amazon and the Brazilian Cerrado, where Maranhão is located.

KEYWORDS: Legal Amazon. Brazilian Cerrado. Transition area. Burnt focus. Dry / rainy period

\section{INTRODUÇÃO}

Em todo o planeta, as queimadas destroem milhares de hectares dos ecossistemas proporcionado impactos ambientais e na saúde pública, provocando severos prejuízos econômicos e ambientais (JUSTINO, 2002; IMESC, 2015). Segundo o IMESC (2017), no território brasileiro, o fogo ainda é bastante utilizado no manejo de pastagem e na "limpeza dos terrenos" para a agricultura tradicional, sendo uma forma rápida e barata de reduzir a biomassa, estimular a rebrota de forragem para a pecuária, diminuir as pragas e remover os remanescentes agrícolas, no Maranhão esta técnica é largamente utilizada na agricultura familiar, sendo conhecida como "roça no toco". Porém, no período de estiagem ou de eventos de secas mais severas, a vegetação está mais suscetível, e a queimada mesmo sendo feita de forma controlada pode tomar proporções desastrosas, atingindo áreas de vegetação remanescente, matando animais silvestres e até mesmo avançar sobre áreas rurais e urbanas.

O Maranhão faz parte do Nordeste brasileiro, porém, devido a sua posição geográfica recebe influência tanto do clima úmido da Amazônia quanto do semiárido nordestino, o que levou o Ministério da Integração Nacional (MI) em 2005 a retirar o estado do perímetro oficial do Semiárido Brasileiro (SAB) ${ }^{1}$. Devido à essas características geográficas, o Maranhão apresenta aspectos transicionais que se caracterizam pela presença de três biomas brasileiros distintos: bioma Amazônia, Cerrado e Caatinga.

Uma grande parte do Nordeste brasileiro com inclusão de algumas áreas do estado do Maranhão possui territórios e populações que sobrevivem sob influências ambientais/climáticas severas caracterizadas por eventos de secas e/ou estiagens, diante desta problemática, em 2017, dois municípios maranhenses (Timon e Araioses) foram inseridos no perímetro oficial do SAB. Contudo, levantamentos como o da EMBRAPA (2013) indicam que toda a região Leste do Maranhão apresenta um padrão de clima semiárido em um contexto

\footnotetext{
${ }^{1}$ Contudo, há questionamentos da não inserção do Maranhão como parte integrante do SAB (ELOI, 2007; LEMOS, 2007).
} 
sazonal de pelo menos seis meses. A porção territorial maranhense que pode ser inserida no clima semiárido faz parte de um grupo de áreas chamadas de 'terras secas', que incluem climas diretamente afetados pelas zonas semiáridas e correspondem diretamente nas áreas com maior grau da vulnerabilidade do estado a focos de queimadas.

Através da análise dos focos de queimadas e seus impactos é possível fornecer informações para obtenção de políticas públicas com o objetivo de reduzir os prejuízos causados. Ainda são poucas as publicações que são direcionadas à temática do clima e seus efeitos em eventos de queimadas no território maranhense, dentre estas podem-se mencionar os estudos recentes de Silva et al. (2017) que avaliaram os impactos da seca no Maranhão durante um evento de seca entre 2010-2016 e Aragão et al. (2018) que avaliaram a contribuição das emissões de dióxido de carbono decorrentes de focos de queimadas para toda a área da Amazônia legal. Cabe ressaltar, que ainda existe dificuldade da própria academia maranhense em relação a essa temática, e isso faz com que a participação do Maranhão possa ficar comprometida em ações governamentais voltadas ao combate a cenários de seca extrema, a acesso a água de qualidade e a temas afins como a questão do combate a focos de queimadas; mas este cenário vem sendo alterado nas últimas décadas. A contribuição do presente artigo consiste em promover uma análise específica entre a ocorrência de focos de queimadas e a padrões climáticos do estado em um intervalo temporal de 18 anos.

Nas últimas décadas foram registrados altos valores de focos de queimadas no Maranhão, por exemplo em 2016, o estado alcançou o terceiro lugar no ranking de estados com o maior foco de calor no Brasil, segundo dados do Instituto Nacional de Pesquisas Espaciais (INPE), e tendo como destaque o município de Grajaú como um dos mais afetados por esse tipo de ocorrência no referido ano.

O conceito de vulnerabilidade adotado na presente pesquisa corresponde ao grau de suscetibilidade ou incapacidade de um sistema lidar com os efeitos adversos da mudança no clima, incluindo a variabilidade climática e os eventos extremos de tempo, conforme proposto pelo Painel Intergovernamental de Mudanças Climáticas - IPCC (IPCC, 2013). Destaca-se ainda que, o conceito de vulnerabilidade apresentado pelo IPCC é voltado para os eventos extremos de tempo, que para o caso da presente pesquisa é direcionado a períodos prolongados de estiagem/seca.

Cabe ressaltar que há uma grande lacuna de conhecimento no que se refere ao entendimento dos impactos dos focos de queimadas na região de transição entre os biomas Amazônico e Cerrado, e como as características climáticas transicionais dessa área e as formas de uso e ocupações humanas podem intensificar os efeitos dos impactos presentes.

O objetivo do presente estudo é avaliar a ocorrência sazonal e os impactos dos focos de queimadas no Maranhão, tomando-se como referência o intervalo de tempo compreendido de 1998 a 2016.

\section{MATERIAL E MÉTODOS}


O estado do Maranhão (Figura 1) apresenta grande variedade de ecossistemas devido à sua localização entre o Nordeste e o Norte, ou seja, entre as condições do semiárido brasileiro e o bioma Amazônia, se destacando assim como um verdadeiro conjunto de ambientes transacionais, onde predominam as seguintes formações vegetais: floresta ombrófila densa, savana (Cerrado), savana estépica, floresta estacional decídua, floresta estacional e formações com influência marinha e fluvio marinha (AZEVEDO, 2002).

Um relatório do Macrozoneamento Ecológico-Econômico do Maranhão (EMBRAPA, 2013), utilizando o método de classificação proposto por Thorntwaite (1948), indica que há quatro tipos climáticos identificados no estado, inclusive a região leste do Maranhão apresenta pelo menos seis meses de padrão semiárido. Os quatro tipos climáticos do Maranhão são:

$\checkmark$ Equatorial: quente (média maior que $18^{\circ} \mathrm{C}$ em todos os meses), úmido (3 meses secos);

$\checkmark$ Tropical Brasil Central: quente (média maior que $18{ }^{\circ} \mathrm{C}$ em todos os meses), semiúmido (4 a 5 meses secos);

$\checkmark$ Tropical Zonal Equatorial: quente (média maior que $18{ }^{\circ} \mathrm{C}$ em todos os meses), semiárido (6 meses secos);

$\checkmark$ Tropical Zonal Equatorial: quente (média maior que $18{ }^{\circ} \mathrm{C}$ em todos os meses), semiúmido (4 a 5 meses secos).

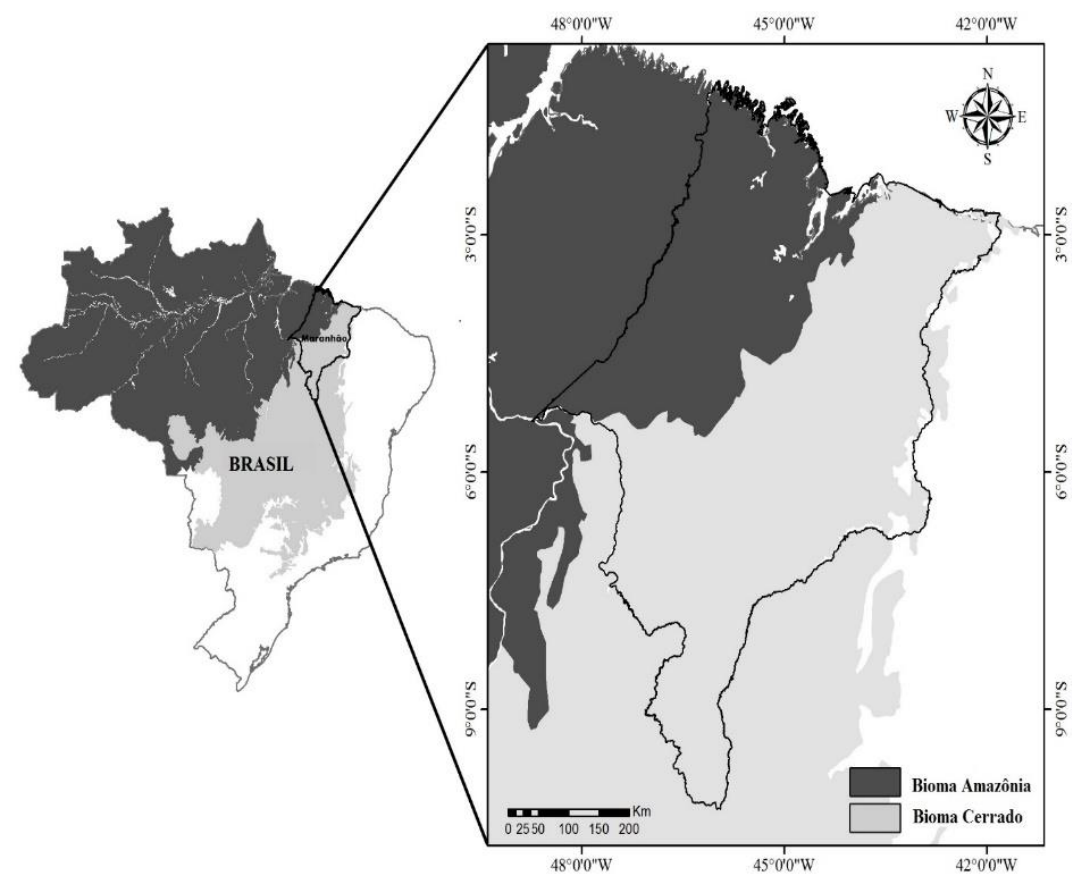

Figura 1 - Área de estudo destacando a localização do estado do Maranhão em uma área de transição entre os biomas Amazônia e Cerrado.Fonte: Instituto Nacional de Pesquisas Espaciais (INPE)

\section{PROCEDIMENTOS METODOLÓGICOS}


A presente pesquisa possui aporte quantitativo, sendo realizado um levantamento de dados sobre focos de queimadas e precipitação para o Maranhão no intervalo de tempo de 1998 a 2016. Os dados de focos de queimadas e de precipitação foram trabalhados com procedimentos estatísticos básicos para o intervalo de tempo considerado, como o cálculo de valores médios mensais e anuais, valores máximos mensais e anuais e o percentual total de cada ano para o período avaliado; com intuito de identificar padrões espaço-temporais entre os focos de queimadas e a ocorrência ou não da precipitação. O Maranhão apresenta duas estações do ano, um período de chuvoso e um outro de estiagem que ocorrem duram aproximadamente seis meses cada um (EMBRAPA, 2013). Dessa forma, o intervalo de tempo de 19982016 foi divido entre um período de seis meses de chuva e um segundo período de seis meses de estiagem, sendo o primeiro período relativo aos meses de janeiro a junho e o segundo período, o fim da estação chuvosa e início da estação seca referente aos meses de julho a dezembro.

Os dados climáticos de precipitação para o período considerado são provindos de 15 estações ${ }^{2}$ meteorológicas do Instituto Nacional de Meteorologia (INMET) através de seu banco de Dados Meteorológico para o Ensino e Pesquisa (BDMEP) . Os dados de focos de queimadas foram oriundos do Instituto Nacional de Pesquisas Espaciais (INPE), através dos satélites de referência de seu Banco de Dados de Queimadas e ambos os conjuntos de dados foram agrupados em séries mensais, de acordo com o período chuvoso e de estiagem do Maranhão.

Além dos dados quantitativos referentes a precipitação e focos de queimadas, também foi realizada uma busca de informações quantitativas/qualitativas em instituições governamentais e não governamentais sobre os impactos socioambientais oriundos dos focos de queimadas no Maranhão e como o governo maranhense responde a tais eventos. Tal busca teve o intuito de promover uma maior compreensão do grau de vulnerabilidade que o Maranhão enfrenta em relação a ventos de focos de queimadas no período de estiagem, e como o estado responde a tais eventos.

\section{RESULTADOS E DISCUSSÃO}

De acordo com estimativas do Instituto Maranhense de Estudos Socioeconômicos e Cartográficos (IMESC), todos os anos o estado do Maranhão apresenta elevada ocorrência de focos de queimadas, quando comparado a outros estados brasileiros. De 1998 a 2016 foram notificados 374.883 focos de queimadas pelos satélites de referência do Programa de Monitoramento de Queimadas do INPE no estado do Maranhão (ver Figura 3), sendo que os anos com maior ocorrência foram 2015 e 2012 com respectivamente 31.595 (8,43\%) e $30.138(8,04 \%)$ dos focos registrados para o período acompanhado na presente pesquisa. Os focos de queimadas para os demais anos comportaramse em termos de quantidade de notificações com os seguintes padrões: 2010 com 28.897 focos $(7,71 \%), 2007 \operatorname{com} 27.096$ focos $(7,21 \%), 2014 \operatorname{com} 25.435$ focos $(6,79 \%), 2005 \operatorname{com} 23.749$ focos $(6,34 \%), 2003$ com $23.382(6,24 \%)$ focos, $2004 \operatorname{com} 22.361$ focos (5,91\%), $2016 \operatorname{com} 21.765$ focos $(5,81 \%), 2002$ com 21.619 focos (5,77\%), 2001 com 18.697 focos (4,99\%), 2013 com 16.188

2 Para conhecimento da localização das estações, acessar:


focos $(4,32 \%), 2011$ com 14.954 focos (3,99\%), 2009 com 14.377 focos $(3,84 \%), 1988 \operatorname{com} 14.237$ focos $(3,80 \%), 2008 \operatorname{com} 11.366$ focos $(3,03 \%)$, 2006 com 11.282 focos (3,01\%), 2000 com 8.983 focos $(2,40 \%)$ e por fim, 0 ano de 1999 com 8.712 focos de queimadas registrados (2,32\%).

De acordo com o Programa de Monitoramento de Queimadas do Instituto Nacional de Pesquisas Espaciais (INPE), todos os anos, o Maranhão possui uma elevada ocorrência de focos de queimadas, sendo um dos estados da Amazônia Legal onde mais ocorre esse fenômeno. Em 2015, por exemplo, ano de maior ocorrência de focos de queimadas para o intervalo temporal considerado na presente pesquisa, o Maranhão ficou em primeiro lugar em ocorrência de focos de queimadas em 48 horas em relação aos demais estados brasileiros, segundo dados do INPE; de janeiro até o mês de dezembro do referido ano, foram registrados pelos satélites cerca de 31.595 focos de queimadas. Todos os biomas maranhenses são afetados pelas queimadas, o que pode causar a perda da diversidade biológica e alterações nos serviços ambientais prestados por estes

Os principais impactos socioambientais oriundos de eventos de estiagem prolongados no Maranhão podem ser sumarizados em dificuldade de acesso a água, perdas nas atividades agropecuárias, perdas de bens matérias, risco à vida humana e potenciais prejuízos a biodiversidade nos biomas e ecossistemas maranhenses (devido a ação das queimadas), a Figura 2 ilustra alguns impactos ocasionados por eventos de estiagem que ocorrem anualmente no Maranhão.

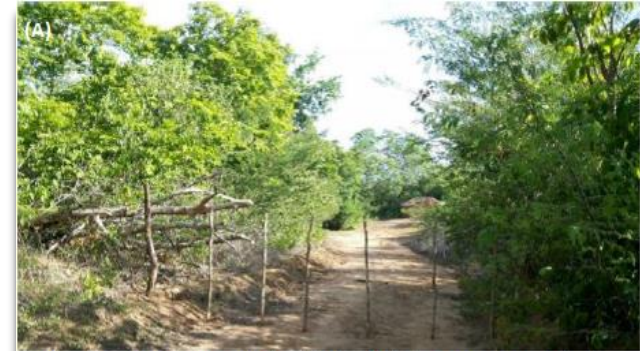

Leito do Balneário Bela Vista no município de Matões, totalmente sem água.

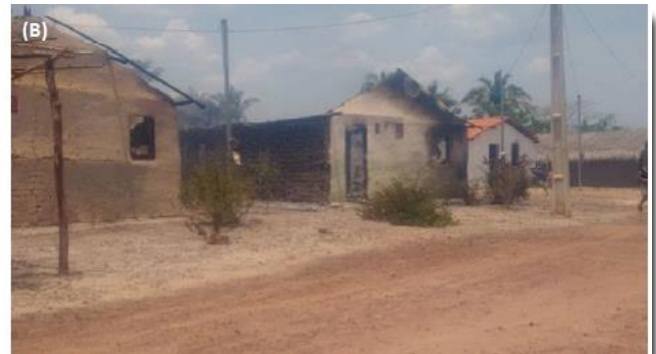

Residenciais queimada no povoado Domingos Ezídio, no município de Gonçalves Dias.

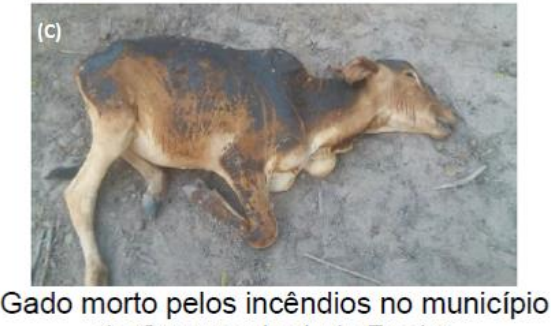
de Governador Luiz Rocha.

Figura 2 - Impactos socioambientais de um evento de estiagem no ano 2016. (A) - Leito de um rio totalmente seco no município de Bela Vista/MA. (B) - Residências totalmente consumidas pelo fogo no munícipio de Gonçalves Dias/MA. (C) - Gado morto pelo fogo no município de Luiz Rocha/MA. Fonte: Fotos cedidas pela Secretária de Estado Meio Ambiente e Recursos Naturais Renováveis do Maranhão (SEMA). 
Um impacto de eventos de estiagens que merece destaque no território maranhense são as queimadas, uma vez que estas podem ser modulados por eventos de secas e/ou estiagens prolongadas no Maranhão, assim como consequência das formas antrópicas de uso e cobertura do solo (IMESC, 2017).

O padrão de ocorrência dos focos de queimadas no Maranhão é modulado pela ocorrência ou não da precipitação (SILVA JUNIOR et al., 2015), ou seja, os padrões de secas e/ou estiagem no Maranhão modulam o fenômeno de queimadas nos biomas maranhenses. Tal cenário ocorre devido ao aumento da inflamabilidade da vegetação, como consequência do déficit hídrico decorrente do período de poucas chuvas (BECERRA; ALVALÁ; SHIMABUKURO, 2008; ARAGÃO et al., 2009), assim como, também, em decorrência das atividades humanas.

Constata-se com os números de focos registrados para o período analisado na presente pesquisa, que estes constituem-se como um expressivo impacto socioambiental no Maranhão oriundo do período de estiagem, e que há uma constância sazonal nesse fenômeno, pois todos os anos no Maranhão há aproximadamente seis meses de período de chuvas e igual período para eventos de estiagem. A Figura 3 apresenta os dados referentes aos focos de queimadas entre 1998 a 2016, para cada mês dos anos monitorados.

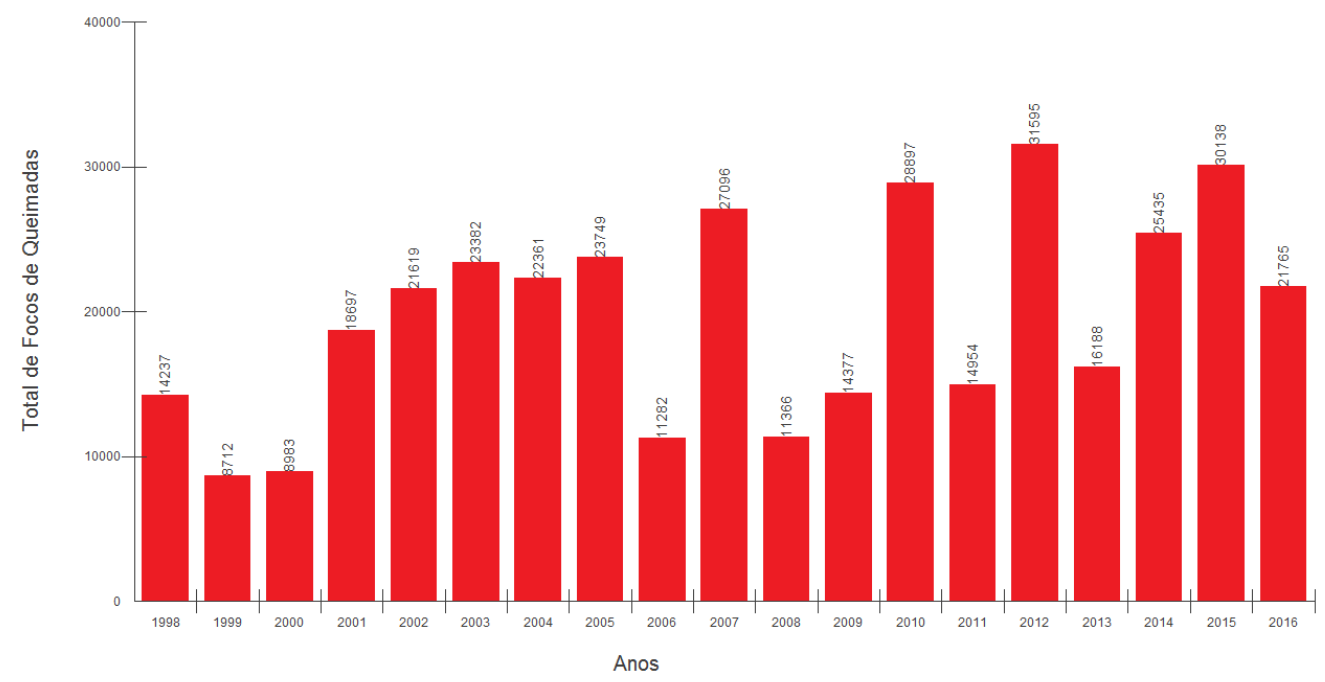

Figura 3 - Focos de queimadas para o período considerado, para cada mês dos anos acompanhados.

Os dados presentes na Figura 3 indicam que há um padrão de ocorrência constante de focos de queimadas para a área estudada, pois em todos os anos é possível observar a presença de eventos de queimadas. Contudo, a predominância de focos de queimadas no Maranhão ocorre nos meses do segundo semestre de cada ano, que correspondem ao período de estiagens (SILVA et al., 2017; IMESC, 2017). Para o período considerado, os focos de queimadas para os meses de fortes chuvas no Maranhão (de janeiro a junho) correspondem a apenas $4,49 \%$ do total, cerca de 16.817 focos registrados; porém, os meses de estiagem totalizam aproximadamente $95,51 \%$ de todo o montante registrados pelo Programa de Monitoramento de Queimadas do INPE, com um valor de 358.016 focos. Os dados apresentados na presente pesquisa indicam um forte padrão sazonal para ocorrência de focos de queimadas no 
Maranhão, o que corrobora com hipótese que os meses de estiagem intensificam os eventos de queimadas em território maranhense.

No decorrer de um ano, o Maranhão apresenta uma variação de $800 \mathrm{~mm}$ a $2800 \mathrm{~mm}$ de distribuição da precipitação pluviométrica (MARANHÃO, 2002), dependendo da área que se tome como referência e o período do ano, se estiagem ou período chuvoso no estado. Isso evidencia um balanço hídrico complexo e que apresenta expressiva variação espacial e principalmente sazonal para a distribuição das chuvas. A Figura 4 destaca a complexidade do balanço hídrico sazonal do Maranhão levando-se em consideração uma série temporal de 30 anos, sendo que na Figura 4 A é destacado o cenário para o mês de abril (pico das chuvas) onde os valores pluviométricos oscilam entre 60 a $460 \mathrm{~mm}$; e a Figura 4 B apresenta o cenário para o mês de julho (período de estiagem já estabelecido) onde os valores que podem ser visualizados variam de 0 a 120 $\mathrm{mm}$, o que evidencia uma expressiva queda na intensidade da precipitação. 


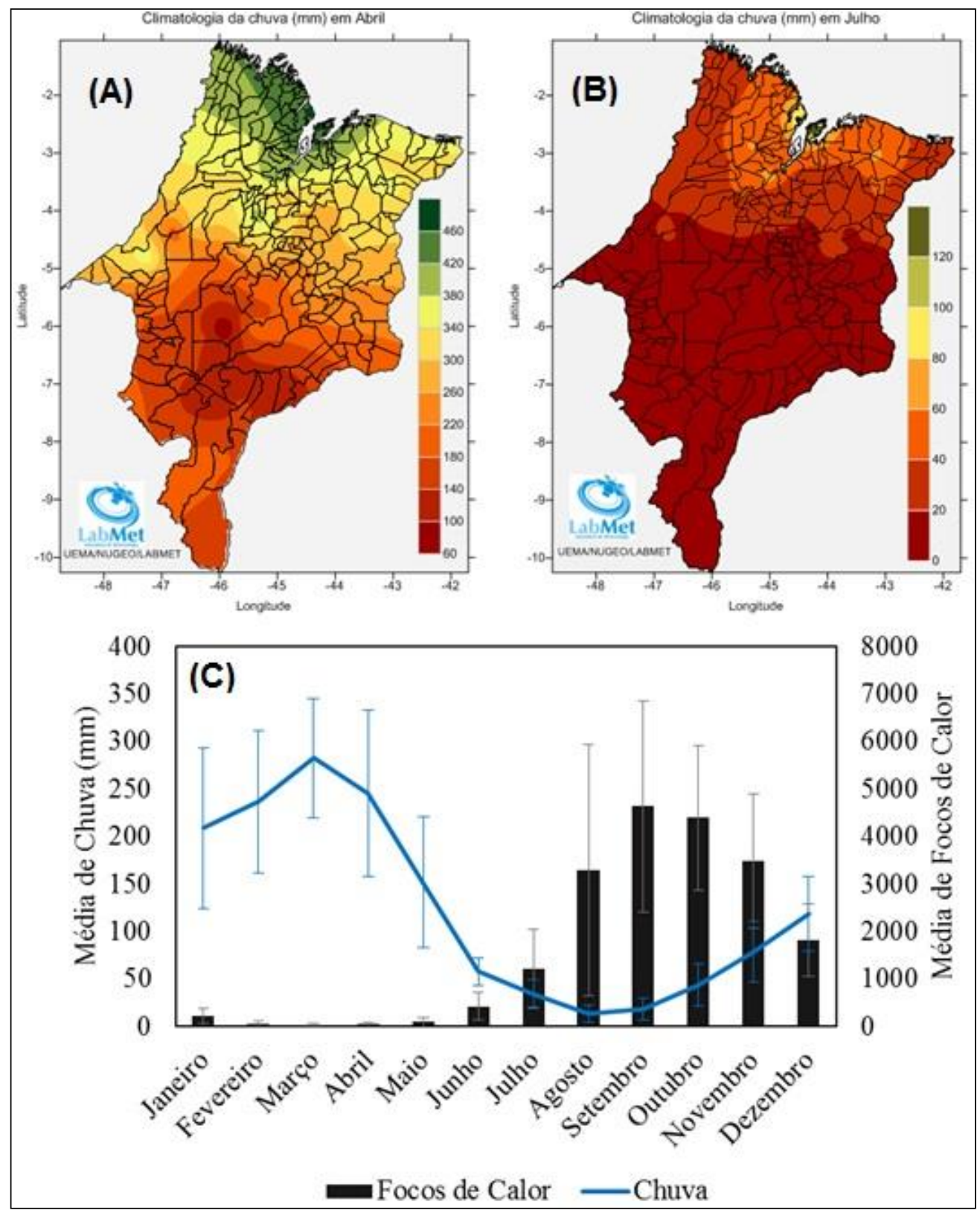

Figura 4 - (A) Padrão pluviométrico para o mês de abril (auge do período chuvoso), para uma série de 30 anos. (B) Padrão pluviométrico para o mês de julho (início do período de estiagem), para uma série de 30 anos (Adaptado de Silva et al., 2013). (C) Relação das médias dos meses de precipitação com os focos de queimadas, período de estiagem e o chuvoso.

No Maranhão devido às suas características históricas de uso e ocupação do solo voltadas em grande parte para a agricultura familiar e de pequeno porte, além de sua expressiva área geográfica, há predomínio de atividades agrícolas com o uso intensivo do sistema de corte e queima, popularmente conhecida como "roça no toco" (MARANHÃO, 2002; SILVA JUNIOR et al., 2017), esta atividade aumenta a chances de ocorrer um foco de queimada, uma vez 
que o fogo pode sair do controle do pequeno agricultor. Contudo, os dados contidos no presente estudo demonstram que o padrão de ocorrência de queimadas é também modulado pelo clima, mais precisamente em relação ao período de estiagem, conforme pode ser observado na Figura $4 \mathrm{C}$, que evidencia que os focos de queimadas são concentrados em sua maior parte nos meses de estiagem no Maranhão, enquanto nos meses de chuvas estes apresentam uma ocorrência bem menor.

Silva et al. (2017) avaliaram a ocorrência de focos de queimadas no Maranhão no intervalo de 2010 a 2016, período onde foi observado um expressivo evento de seca em toda a região do nordeste brasileiro. Na pesquisa os autores também identificaram uma forte relação entre focos de queimadas e o período de estiagem maranhense que se inicia a partir do segunde semestre de cada ano.

Em pesquisa recente, Aragão et al. (2018) examinaram os impactos da seca na Amazônia brasileira sobre a incidência de incêndios e as emissões de carbono associadas a esse processo, no período 2003-2015. Na referida pesquisa foi constatado que apesar de ter ocorrido um declínio de $76 \%$ nas taxas de desmatamento nos últimos 13 anos, a incidência de incêndios aumentou em 36\% durante a seca de 2015 em comparação com os 12 anos anteriores; isso indica que a seca observada no ano de 2015 pode ter influenciado a incidência de incêndios, o que corrobora com o padrão observado para a presente pesquisa.

A população rural é a mais vulnerável ao fenômeno das queimadas, pois devidos às suas características geográficas e socioambientais, as incidências de focos são mais comuns nestas áreas, que normalmente correspondem ao percentual da população com os piores indicadores de qualidade de vida e quem tem mais dificuldade para obter suporte por meio de políticas governamentais. A Tabela 1 apresenta o número de pessoas e municípios afetados por eventos de seca durante o período de 2010 a 2016 que foram acompanhados pelos Comando Geral do Corpo de Bombeiros do Maranhão (CGCB/MA).

Tabela 1 - Número de pessoas e de municípios maranhenses afetados eventos de secas para o período de 2010 a 2016.

\begin{tabular}{ccc} 
Ano & Municípios afetados & $\begin{array}{c}\text { Pessoas afetadas (direta } \\
\text { e indiretamente) }\end{array}$ \\
2010 & 51 & 90.800 \\
2011 & 29 & 75.650 \\
2012 & 69 & 227.000 \\
2013 & 86 & 317.000 \\
2014 & 20 & 71.495 \\
2015 & 22 & 155.274 \\
2016 & 24 & 239.461 \\
Total acumulado & 301 & 1.176 .680 \\
\hline
\end{tabular}

Fonte: CGCB/MA (2016)

O município maranhense de maior recorrência a eventos de estiagens prologadas no período de 2010-2016 foi Grajaú, e logo em seguida, os seguintes municípios: Centro Novo do Maranhão, Bom Jardim, Itinga do Maranhão, Açailândia, Turilândia, Buriticupu, Santa Luzia, Cândido Mendes e Balsas. Contudo, cabe ressaltar não apenas os municípios mencionados como 
vulneráveis, pois nas últimas décadas vários outros municípios decretaram estado de emergência como resposta a estiagens em território maranhense.

Durante o último período de estiagem extrema observado no Maranhão entre 2010 a 2016, um total de 1.176 .680 pessoas foram direta ou indiretamente afetadas em vários municípios, o que evidencia a necessidade de haver eficiência nos serviços públicos de atendimento à população maranhense, assim como, também, demonstra que há uma grande demanda por pesquisa em várias áreas do conhecimento humano, para minimizar e/ou mitigar os efeitos das secas e/ou estiagens no Maranhão.

Somente no ano de 2016, o CGCB/MA estima que foram perdidas 46 moradias em decorrência das queimadas no território maranhense, outras 110 sofreram danos parciais. Os prejuízos financeiros, ainda de acordo com 0 CGCB/MA, somam valores da ordem de: $R \$ 1.420 .385,00$ no comércio, $R \$$ 4.093.729,56 na agricultura e $\mathrm{R} \$ 10.202 .230,60$ na pecuária.

Silva et al. (2017) chamam a atenção para outro importante indicador dos impactos das estiagens sazonais no Maranhão, o número de decretações de situação de emergência em decorrência de eventos de secas severas no Maranhão, que segundo estimativas do CGCB/MA, totalizaram 207 decretos para o período de 2010 a 2016; sendo 77 decretações municipais e 130 decretações estaduais. A Figura 5 apresenta distribuição espacial de todos os municípios maranhenses que já decretaram estado de emergência como resposta a eventos de secas ou estiagens prolongadas no período de 1991 a 2010. 


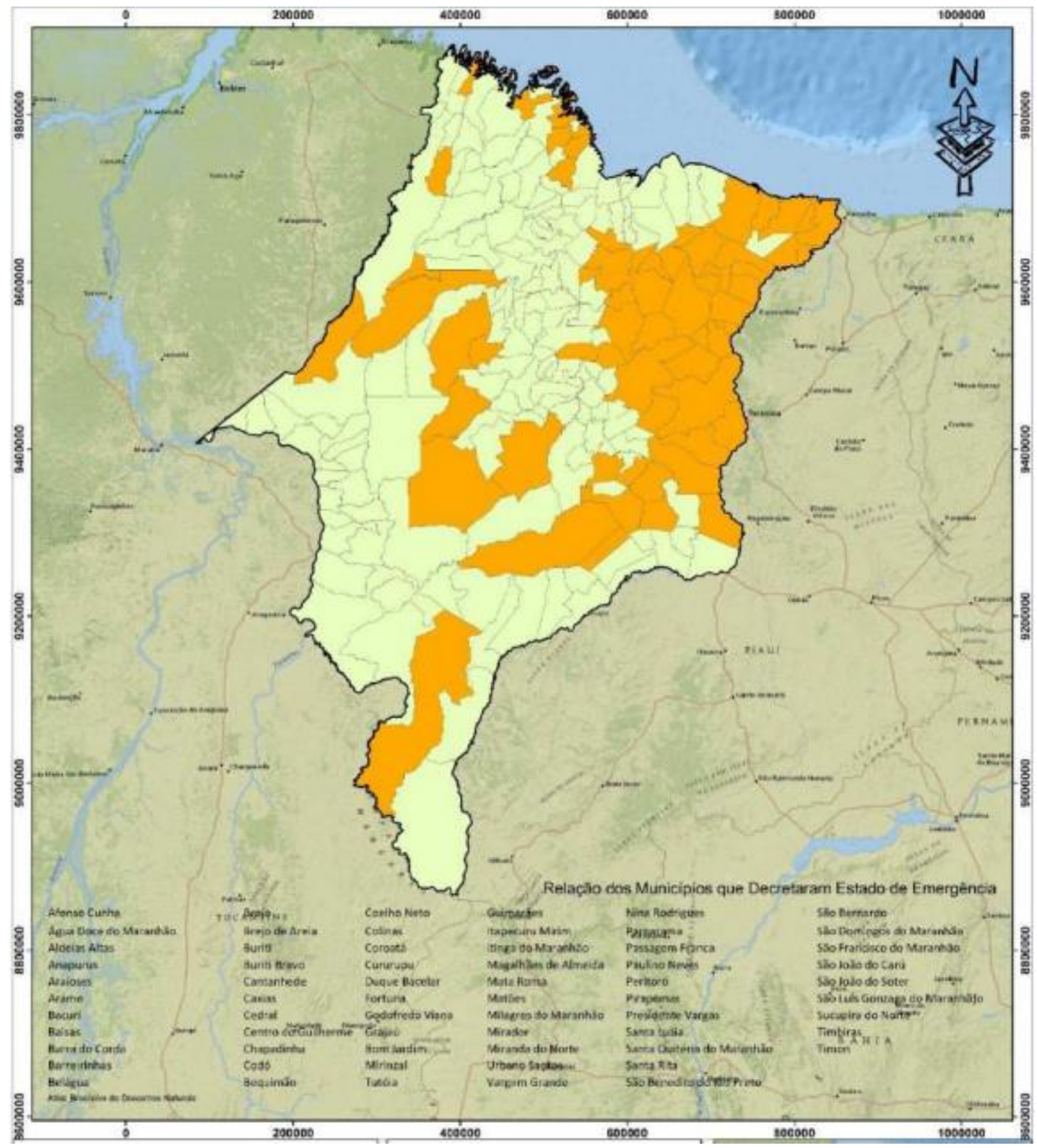

Figura 5 - Municípios maranhenses que já decretaram estado de emergência a eventos de secas entre 1991 a 2010. Fonte: Adaptado de IMESC (2016)

Todos os munícipios listados na Figura 4 são afetados pelo período de estiagem e redução da precipitação, porém, a intervenção do homem e a sua cultura de plantio também são fatores importantes para intensificação da vulnerabilidade do estado a ocorrência de queimadas.

Além do entendimento de como o padrão sazonal do clima maranhense pode influenciar a ocorrência de focos de queimadas, é necessária avaliação de como a população e os tomadores de decisão se organizam para enfrentar esse impacto anual oriundo dos eventos de estiagens. Cabe também ressaltar que para a presente pesquisa, entende-se que eventos de secas e/ou estiagens 
prologadas podem ser influenciados por mudanças climáticas induzidas por atividades antrópicas, assim, as ações governamentais e não governamentais para combate aos seus impactos negativos no Maranhão são analisadas mediantes ao conceito de adaptação da Política Nacional Sobre Mudança do Clima (PNSM). Ou seja, a adaptação pode ser entendida como um conjunto de respostas aos potenciais impactos atuais da mudança do clima, tendo por meta reduzir eventuais danos e ainda promover oportunidades (BRASIL, 2008).

O PNSM indica que a capacidade de adaptação de um sistema depende basicamente de duas variáveis: a vulnerabilidade e a resiliência. A vulnerabilidade é o reflexo do grau de suscetibilidade do sistema para lidar com os efeitos adversos da mudança do clima, enquanto que a resiliência é a habilidade que o sistema tem em absorver os impactos preservando a mesma estrutura básica e os mesmos meios de funcionamento.

Os programas governamentais maranhenses de apoio a eventos de estiagem auxiliam à resiliência da população ao promoverem mais condições à população para resistirem. Contudo a sociedade maranhense não é apenas um elemento inerte que recebe o suporte do estado, mas também, apresenta projetos que visam minimizar os impactos de eventos de estiagens no Maranhão.

De acordo com Silva et al. (2017), os programas maranhenses governamentais e não governamentais de adaptação a eventos de secas e/ou estiagens prolongadas podem ser subdivididos em três categorias: de acesso a água, planejamento e de intervenção em obras de engenharia. As ações de acesso a água se caracterizam por ações do governo estadual, federal e/ou da sociedade civil organizada com intuito de aumentar a oferta de água (em quantidade e qualidade) mesmo em períodos prolongados de secas. As ações de planejamento caracterizam-se por apresentar elaboração de planos, projetos e de dados direcionados de forma direta ou indireta à temática da seca e temas correlatos. E por fim, ações de intervenção de obras de engenharia referem-se a ações governamentais que necessitam de intervenções de atividades de engenharia para sua implementação, tais como barragens, cisternas, canais etc. A Tabela 2 sintetiza os principais programas governamentais e não governamentais de combate a eventos de secas e/ou estiagem em território maranhense. 
Tabela 2 - Principais programas governamentais e não governamentais de combate a eventos de seca no território maranhense.

\begin{tabular}{|c|c|c|c|c|c|}
\hline PROJETO / AÇÃO & RESPONSÁVEL & $\begin{array}{l}\text { FINANCIAME } \\
\text { NTO }\end{array}$ & INÍCIO & CATEGORIA & META \\
\hline $\begin{array}{l}\text { Programa } 1 \\
\text { Milhão de } \\
\text { Cisternas }\end{array}$ & $\begin{array}{l}\text { Articulação do } \\
\text { Semiárido } \\
\text { (ASA/MA) }\end{array}$ & $\begin{array}{c}\text { Sociedade } \\
\text { Civil }\end{array}$ & 1980 & Acesso a Água & $\begin{array}{c}\text { Acesso a } \\
\text { água por } \\
\text { meio da } \\
\text { construção } \\
\text { de } \\
\text { cisternas. }\end{array}$ \\
\hline $\begin{array}{c}\text { Plano de Ação } \\
\text { para Prevenção } \\
\text { e Controle do } \\
\text { Desmatamento } \\
\text { e das } \\
\text { Queimadas no } \\
\text { Estado do } \\
\text { Maranhão. }\end{array}$ & $\begin{array}{c}\text { Secretaria de } \\
\text { Estado do Meio } \\
\text { Ambiente e } \\
\text { Recursos Naturais } \\
\text { Renováveis (SEMA). } \\
\text { Apoio do Ministério } \\
\text { do Meio Ambiente } \\
\text { (MMA). }\end{array}$ & $\begin{array}{l}\text { Banco Mundial } \\
\text { e Governo da } \\
\text { Noruega. }\end{array}$ & 2011 & Planejamento & $\begin{array}{c}\text { Planejamen } \\
\text { to de ações } \\
\text { ao combate } \\
\text { ao } \\
\text { desmatame } \\
\text { nto e a } \\
\text { ocorrência } \\
\text { de } \\
\text { queimadas } \\
\text { no } \\
\text { Maranhão. }\end{array}$ \\
\hline $\begin{array}{c}\text { Programa de } \\
\text { Ação Estadual } \\
\text { de Prevenção e } \\
\text { Combate a } \\
\text { Desertificação e } \\
\text { Mitigação dos } \\
\text { Efeitos da Seca } \\
\text { do Estado do } \\
\text { Maranhão - PAE }\end{array}$ & $\begin{array}{c}\text { Instituto } \\
\text { Maranhense de } \\
\text { Meio Ambiente e } \\
\text { Recursos Hídricos } \\
\text { (IMARH). Secretaria } \\
\text { de Estado do Meio } \\
\text { Ambiente e } \\
\text { Recursos Naturais } \\
\text { Renováveis (SEMA). }\end{array}$ & $\begin{array}{l}\text { Ministério do } \\
\text { Meio Ambiente } \\
\text { (MMA). }\end{array}$ & 2012 & Planejamento & $\begin{array}{c}\text { Planejamen } \\
\text { to de ações } \\
\text { ao combate } \\
\text { à } \\
\text { desertificaç } \\
\text { ão e aos } \\
\text { efeitos da } \\
\text { seca no } \\
\text { Maranhão. }\end{array}$ \\
\hline
\end{tabular}

(MA) $\begin{array}{ccc}\begin{array}{c}\text { Programa Água } \\ \text { Doce no }\end{array} & \begin{array}{c}\text { Secretária da } \\ \text { Agricultura Familiar Meio Ambiente }\end{array} \\ \begin{array}{ccc}\text { Maranhão (PAD) } & \text { (SAF). } & \text { (MMA). }\end{array}\end{array}$
Programa

Cisternas (Segunda Água)
Secretária da Ministério do Agricultura Familiar Meio Ambiente (SAF).

(MMA).

\begin{tabular}{|c|c|c|}
\hline $\begin{array}{c}\text { Barragens de } \\
\text { Contenção na } \\
\text { Baixada } \\
\text { Maranhense }\end{array}$ & $\begin{array}{l}\text { Responsável: } \\
\text { Secretária de } \\
\text { Estado de } \\
\text { Desenvolvimento } \\
\text { Social (SEDES) }\end{array}$ & $\begin{array}{c}\text { Governo do } \\
\text { Estado do } \\
\text { Maranhão. }\end{array}$ \\
\hline
\end{tabular}

2016

Acesso a água

Dessalinizaç ão de poços

d'água do ambiente

rural.

Acesso a água

Acesso a água por meio da construção de cisternas no meio rural.

Obras de engenharia.

Orientar a construção de barragens para retenção da água no período chuvoso na Baixada Maranhense 


\begin{tabular}{|c|c|c|c|c|c|}
\hline $\begin{array}{c}\text { Projeto de } \\
\text { Construção de } \\
\text { Canais de } \\
\text { Acumulação de } \\
\text { Água }\end{array}$ & $\begin{array}{l}\text { Responsável: } \\
\text { Secretária de } \\
\text { Estado de } \\
\text { Desenvolvimento } \\
\text { Social (SEDES) }\end{array}$ & $\begin{array}{l}\text { Governo do } \\
\text { Estado do } \\
\text { Maranhão. }\end{array}$ & 2016 & $\begin{array}{c}\text { Obras de } \\
\text { engenharia. }\end{array}$ & $\begin{array}{c}\text { Orientar a } \\
\text { construção } \\
\text { de canais } \\
\text { para } \\
\text { retenção da } \\
\text { água no } \\
\text { período } \\
\text { chuvoso na } \\
\text { Baixada } \\
\text { Maranhense } \\
\text {. }\end{array}$ \\
\hline $\begin{array}{l}\text { Zoneamento } \\
\text { Agropecuário do } \\
\text { Maranhão } \\
\text { (ZAMA) }\end{array}$ & $\begin{array}{l}\text { Secretária da } \\
\text { Agricultura, } \\
\text { Pecuária e } \\
\text { Abastecimento } \\
\text { (SAGRIMA). }\end{array}$ & $\begin{array}{l}\text { Governo do } \\
\text { Estado do } \\
\text { Maranhão. }\end{array}$ & 2016 & Planejamento & $\begin{array}{l}\text { Minimizar } \\
\text { os riscos } \\
\text { relacionado } \\
\text { s aos } \\
\text { fenômenos } \\
\text { climáticos. }\end{array}$ \\
\hline $\begin{array}{c}\text { Seminário } \\
\text { Maranhense de } \\
\text { Mudanças } \\
\text { Climáticas }\end{array}$ & $\begin{array}{c}\text { Secretaria de } \\
\text { Estado do Meio } \\
\text { Ambiente e } \\
\text { Recursos Naturais } \\
\text { Renováveis (SEMA). }\end{array}$ & $\begin{array}{l}\text { Governo do } \\
\text { Estado do } \\
\text { Maranhão. }\end{array}$ & 2017 & Planejamento & $\begin{array}{c}\text { Promover a } \\
\text { discussão e } \\
\text { entendimen } \\
\text { to da } \\
\text { vulnerabilid } \\
\text { ade do } \\
\text { Maranhãos } \\
\text { aos } \\
\text { impactos } \\
\text { das } \\
\text { mudanças } \\
\text { climáticas. }\end{array}$ \\
\hline
\end{tabular}

Fonte: Adaptado de Silva et al. (2017)

As ações de combate a eventos de secas e/ou estiagem no território maranhense remontam a década de 1980 através das ações da sociedade civil organizada através da ASA/MA que vem construindo cisternas de capitação da água da chuva, através do programa denominado de 1 milhão de cisternas. Este modelo da sociedade civil organizada foi adotado pelo governo maranhense, que começou a promover a construção de cisternas para coleta da água durante a precipitação no período chuvoso. Nos últimos anos têm ocorrido várias ações governamentais para combate a eventos de estiagens no Maranhão com metas distintas e bem especificas como pode ser observar na Tabela 2.

A ocorrência, frequência sazonal e impactos provocados pelas queimadas anualmente no Maranhão induziram a necessidade da sociedade maranhense de promover um plano estadual de ação de combate/prevenção às queimadas e ao processo de desmatamento. Este documento constitui-se um marco para o estado e demonstra que as queimadas recorrentes no Maranhão correspondem a um sério de problema socioambiental, que demandam políticas públicas e geração de conhecimento adequados para a garantia da qualidade de vida humana e para a qualidade ambiental maranhense.

\section{CONCLUSÃO}

Anualmente ocorrem no Maranhão um valor médio de cerca de 19.729 focos de queimadas anuais em toda sua área que ocasionam vários impactos ambientais e socioeconômicos, nas últimas décadas esse processo vem chamando a atenção do Governo maranhense e da sociedade em geral. 
Os dados discutidos na presente pesquisa indicam que as queimadas se constituem como um fenômeno de ocorrência anual, pois esteve presente durante todo o intervalo temporal monitorado (1998 a 2016). Contudo, percebese um padrão sazonal bem estabelecido para a ocorrência desses focos no território maranhense, uma vez que, o estado apresenta aproximadamente 6 meses de período chuvoso (de janeiro a junho) e seis meses de estiagem (de junho a dezembro), e os focos de queimadas parecem ser modulados por estes eventos, sendo a menor ocorrência dos focos de queimadas para o período chuvoso, que correspondeu $4,49 \%$ do total verificado entre 1998-2016, e a maior ocorrência para o período de estiagem, que correspondeu $90,51 \%$ do total verificado entre 1998-2106; cabe ressaltar que esse padrão merece ser melhor estudado e compreendido pela literatura científica. Além do fator clima, as formas de uso e ocupação do solo de origem antrópica, sobretudo as oriundas da agricultura familiar na zona rural podem influenciar o fenômeno das queimadas maranhenses.

A análise dos dados do presente estudo não indica que as queimadas são decorrentes do período de estiagem que anualmente ocorrem no Maranhão, mas o período de baixíssima precipitação proporciona as condições ambientais ideais para a intensificação das queimadas ocorrentes no estado.

Todos os anos, os impactos provocados pelas queimadas no Maranhão provocam prejuízos em várias dimensões (social, econômica e ambiental), contudo sua mensuração não constitui uma tarefa trivial, o que implica afirmar que há uma grande lacuna de conhecimento sobre os efeitos das queimadas sazonais presentes na área de transição entre a Amazônia Legal e o Cerrado brasileiro, onde o Maranhão está localizado.

\section{REFERÊNCIAS}

ARAGÃO, L. E. O. C. et al. Interactions between rainfall, deforestation and fires during recent years in the Brazilian Amazonia. Philosophical transactions of the Royal Society of London. Series B, Biological Sciences, v. 363, n. 1498, p. 177985,27 maio/2009.

ARAGÃO, L. E. O. C. et al. 21st Century drought-related fires counteract the decline of Amazon deforestation carbon emission. Nature communications I (2018) 9:536. DOI: 10.1038/s41467-017-02771-y.

AZEVEDO, A. C. G. Ecossistemas maranhenses série ecológica: 1. São Luís, MA: UEMA Editora, 2002.

BECERRA, J. A. B.; Alvalá, R. C. dos S.; Shimabukuro, y. precipitação, fogo e índices de vegetação na detecção de fisionomias de Savana Tropical na Região Amazônica Brasileira. In: SIMPÓSIO INTERNACIONAL DE SAVANAS TROPICAIS, 2. 2008, Brasília. Anais... Brasília: 2008.

BRASIL - Plano Nacional Sobre Mudança do Clima (PNMC). Comitê Interministerial Sobre Mudança do Clima. Decreto no 6.263, de 21 de novembro de 2007. Brasília, dezembro de 2008, 132.

ELOI, C. M. A. Ocorrência de Semiárido Dentro do Maranhão no Município de Grajaú Segundo a Equação Definida Pela Convenção das Nações Unidades de 
Combate à Desertificação (UNCCD). Anais do XV Congresso de Agrometeorologia, 02 a 05 de Julho de 2007, 5 p.

EMBRAPA. Relatório do diagnóstico do macrozoneamento ecológico-econômico do Estado do Maranhão / Mateus Batistella, Édson Luis Bolfe, Luiz Eduardo Vicente, Daniel de Castro Victoria, Luciana Spinelli Araujo (Org.). - Campinas, SP: Embrapa, 2013. 325 p.

IMESC, Instituto Maranhense de Estudos Socioeconômicos e Cartográficos. Análise da Incidência de Focos de Queimadas nas Terras Indígenas do Estado do Maranhão. In: Relatório Técnico. IMESC. São Luís, 2015.

IMESC, Instituto Maranhense de Estudos Socioeconômicos e Cartográficos. Análise da Seca e Estiagem Maranhense. In: Relatório Técnico. IMESC. São Luís, 2016.

IMESC, Instituto Maranhense de Estudos Socioeconômicos e Cartográficos. Relatório: Queimadas maranhenses - 1a trimestre 2017. In: Relatório Técnico. IMESC. São Luís, 2017.

IPCC. Working group I Contribution to the IPCC fifth assessment Report (AR5), climate change 2013: the physical science basis. Cambridge Univ. Press, 2013. 2216p.

JUSTINO, F. B. Relação entre "Focos de Calor" e Condições Meteorológicas no Brasil. In: XII Congresso Brasileiro de Meteorologia. Foz de Iguaçu-PR, 2002.

LEMOS, J. J. S. Inserção do Maranhão no Semiárido do Brasil. 2007, 21p. Disponível em: <http://www.lemos.pro.br/admin/artcientifico/124111604949f9ed91495d2.pdf. >. Acesso: 22/04/2017.

MARANHÃO - Atlas do Maranhão/Gerência de planejamento e desenvolvimento econômico, Laboratório de Geoprocessamento (LABGEO/UEMA). São Luis: GEPLAN. 2002, 36 p.

SILVA JUNIOR, C. H. L. et al. A zona de transição entre a Amazônia e o Cerrado no estado do Maranhão. Parte II: Caracterização preliminar dos dados de área queimada (Produto MODIS MCD45A1). In: SIMPÓSIO BRASILEIRO DE SENSORIAMENTOSIMPÓSIO BRASILEIRO DE SENSORIAMENTO, 17, 2015, João Pessoa. Anais... João Pessoa: INPE, 2015.

SILVA, M. N. et al. A seca no Maranhão no período de 2010 a 2016 e seus impactos. Parc. Estrat. Brasília-DF, v. 22, n. 44, p. 119-138, jan-jun, 2017.

THORNTHWAITE, C. W. An approach towards a rational classification of climate. Geographycal Review, London, v. 38, n. 1, jan. 1948. 